arguments and in the interests of a better quality of debate on important issues.

MIND

22 Harley Street

London WI

DeAR Sirs

I always read with interest the Special Reports published by MIND and am familiar with those mentioned by Mr Lacey.

Like many other psychiatrists, however, I sometimes feel that MIND, both national and local, campaigns with a zeal which does not always recognise the real constraints that the mentally ill, their families and their psychiatrists have to work within.

In some campaigns both ECT and drugs have been roundly condemned when what is needed is greater discrimination in their use. The report on ECT recognised that and I applauded it.

University Department of Psychiatry

SYDNEY BRANDON

Leicester Royal Infirmary

Leicester

\section{Training assessment visits}

\section{DeAr SiRs}

As most of your readers are well aware, the Joint Committee on Higher Psychiatric Training lays a very strong emphasis on trainee representation on its visits to senior registrar training schemes. In the past such representation has sometimes been restricted to trainees from a few training schemes. In order to widen this representation, may I, through your correspondence columns, urge senior registrars to forward their names to me for inclusion on training assessment visits. Trainees' participation in such an exercise is vital if the improvement in their training is to continue. Participation in such visits enables one to not only understand how the other half lives but also gives invaluable insight into one's own training.

The Maudsley Hospital

DiNESH BHUGRA

Denmark Hill

London SE5 8AZ

\section{Groups in a mental handicap hospital}

DEAR SIRS

I read with interest Dr Lovett's article on 'The Life of a Group on a Locked Ward' (Psychiatric Bulletin, February 1989, 13, 60-62). I was involved with two similar groups in a mental handicap hospital; a group each on a male and female ward with behaviourally disturbed patients with mild to moderate handicap.

Some of the difficulties outlined by Dr Lovett were apparent in the above groups. In particular, there were difficulties about the same nurses attending each week due to their shifts. In addition, patients would walk in and out of the group, and due to poor punctuality on both patients' and staffs' parts, the group would often commence late.

I experienced other difficulties also. Firstly, there was difficulty in making interpretations and following the group process in view of patients' mild and moderate handicap. Secondly, the ward staff adopted an approach whereupon patients were requested not to express negative views. It was difficult to persuade the experienced ward staff to change their long-standing views.

Despite the difficulties, the groups appeared to be useful and valuable. The conclusions reported by $\mathrm{Dr}$ Lovett appeared very appropriate.

Shenley Hospital

A. K. SHAH

Shenley, Radlett

Hertfordshire 